\title{
VHF radar observations of the dip equatorial E-region during sunset in the Brazilian sector
}

\author{
C. M. Denardini, M. A. Abdu, E. R. de Paula, C. M. Wrasse, and J. H. A. Sobral \\ Instituto Nacional de Pesquisas Espaciais - P.O. Box 515 - S. J. Campos, SP, Brazil \\ Received: 17 August 2005 - Revised: 9 September 2005 - Accepted: 17 May 2006 - Published: 3 July 2006
}

\begin{abstract}
Using the RESCO $50 \mathrm{MHz}$ backscatter radar $\left(2.33^{\circ} \mathrm{S}, 44.2^{\circ} \mathrm{W}\right.$, DIP: -0.5$)$, at São Luís, Brazil, we obtained Range Time Intensity (RTI) maps covering the equatorial electrojet heights during daytime and evening. These maps revealed a scattering region at an altitude of about $108 \mathrm{~km}$ during the sunset period. The type of 3-m irregularity region we present here has not been reported before in the literature, to our knowledge. It was mainly observed around the Southern Hemisphere summer-solstice period, under quiet magnetic activity condition. The occurrence of this echo region coincides in local time with the maximum intensity of an evening pre-reversal eastward electric field of the ionospheric $F$-region. A tentative explanation is proposed here in terms of the theory of the divergence of the equatorial electrojet (EEJ) current in the evening ionosphere presented by Haerendel and Eccles (1992), to explain the partial contribution of the divergence to the development of the pre-reversal electric field. The theory predicts an enhanced zonal electric field and hence a vertical electric field below $300 \mathrm{~km}$ as a consequence of the EEJ divergence in the evening. The experimental results of the enhanced echoes from the higher heights of the EEJ region seem to provide evidence that the divergence of the EEJ current can indeed be the driver of the observed scattering region.
\end{abstract}

Keywords. Ionosphere (Equatorial ionosphere; Ionospheric irregularities) - Radio science (Ionospheric physics)

\section{Introduction}

The interaction of the neutral atmosphere, ionosphere, and nearly horizontal magnetic field provides one of the most remarkable phenomena of the equatorial ionosphere: the plasma irregularities/structuring of the equatorial $E$ - and

Correspondence to: C. M. Denardini

(denardin@dae.inpe.br)
$F$-region, widely known as the equatorial electrojet (EEJ) irregularities and the equatorial spread-F (ESF). These irregularities have been studied extensively, both experimentally and theoretically in the last decades. Abdu (2001) has pointed out that the evening pre-reversal electric field enhancement plays an important role in the ESF development. The pre-reversal enhancement (PRE) in the zonal electric field is a manifestation of the coupling between the $E$ - and $F$-region in the evening ionosphere, which has been investigated by several authors in recent years (Çakir et al., 1992; Abdu, 1999; Abdu et al., 2003). The average structure of the equatorial electric fields, regarding their roles on the $E$ and $F$-region irregularity developments, has been well documented through many experimental and statistical studies (see, for example, Fejer, 1981). However, the current-electric field relationship is not yet completely understood. Haerendel and Eccles (1992) assert that the equatorial $E$ region plays an important role in determining the electric field in the equatorial ionosphere for several hundred kilometers above it during the evening hours. In this work, we will present evidence on the consistent presence of a scattering region at the $E$-region height during quiet time, which occurs very close to the time of the maximum intensity of the PRE at the $F$ region.

We have analyzed the observational data of the coherent backscatter echoes from the EEJ region obtained from a 50$\mathrm{MHz}$ radar during 2002. A comparison of the results for a group of quiet days with those of a group of disturbed days shows that the occurrence of the scatter region is disturbance dependent. We also deduced the EEJ intensity in terms of the $\mathrm{H}$ component variations at ground magnetometers, in order to check for any possible signature in the $\mathrm{H}$ variation at the time of the occurrence of the scattering region. A tentative explanation for this observational result is presented in terms of an electro-dynamic connection between the $E$ - and $F$-region, in line with the theory proposed by Haerendel and Eccles (1992).

Published by Copernicus GmbH on behalf of the European Geosciences Union. 
Table 1. Data classification according to the magnetic activity around the South Hemisphere summer solstice in 2002.

\begin{tabular}{lll}
\hline $\begin{array}{l}\text { Magnetic } \\
\text { Activity }\end{array}$ & Months & Days \\
\hline Quiet & January & $21,22,23,28,29,30$ \\
& November & $14,15,16,18,19,26,28,29$ \\
& December & $2,3,5,6,9,10,11,12$ \\
Disturbed & January & None \\
& November & $13,17,20,22,23,24,25,27,30$ \\
& December & $1,4,7,8$ \\
\hline
\end{tabular}

\section{Data and method of analysis}

The RESCO (which is an acronym for Radar de ESpalhamento COerente, in English Coherent Scatter Radar) $50-\mathrm{MHz}$ coherent backscatter radar is sensitive to fieldaligned plasma irregularities of a 3-m scale size. It is located at São Luís - SLZ $\left(2.3^{\circ} \mathrm{S}, 44.2^{\circ} \mathrm{W}\right.$, DIP: -0.5$)$, very close to the dip equator in Brazil. It is operated with the beam tilted $30^{\circ}$ westward from vertical, in the E-W plane. The estimated theoretical beam width is $7.4^{\circ}$. The height range used for the EEJ observations is from about 80 to $120 \mathrm{~km}$. The radar was operated at a peak power of $40 \mathrm{~kW}$, with the pulse width set to $20 \mu \mathrm{s}$ and the interpulse period of $1 \mathrm{~ms}$ to avoid ambiguity in the echo detection. The backscattered signals are sampled at $20 \mu \mathrm{s}$, which corresponds to range sampling at $3 \mathrm{~km}$ in the oblique direction which corresponds to $\sim 2.6 \mathrm{~km}$ in terms of height. Each echo is divided into 16 sampling gates, which correspond to 16 height samples. For more detailed information about this radar system see, for example, Abdu et al. (2002) and Denardini et al. (2004).

The radar data analysis produces one spectrogram per sampled height, which consists of a contour map of Doppler frequency versus local time, with a color-coding used to indicate the spectral power. Integration in the Doppler frequency for each spectrogram results in time variations of the total echo power for a specific range gate. Arranging all resulting echo power time variation in a graph of height (gate) versus time produces a daily Range-Time-Intensity (RTI) map. Averaging the RTI maps as a function of local time for all the days in a period of study produces a mean RTI map representing the selected days.

Diurnal variations of the EEJ strength were monitored using the difference of the $\mathrm{H}$ component variations $(\Delta \mathrm{H}$ variation), measured by magnetometers at São Luís $\left(2.3^{\circ} \mathrm{S}\right.$, 44.2 $2^{\circ} \mathrm{W}$, DIP: -0.5$)$ and Eusébio $\left(3.89^{\circ} \mathrm{S}, 38.44^{\circ} \mathrm{W}\right.$, DIP: 12.5) stations. Averaging the $\Delta \mathrm{H}$ variations for all the days indicates the mean EEJ intensity variation induced at the ground level for the selected group of days.

The $K_{p}$ index was used as an indicator of the magnetic activity. If the index reached values above $3^{+}$at any time dur- ing a day, the corresponding day was classified as disturbed. Following the above criteria, we have selected some days in January, November and December 2002, around the summer solstice for the Southern Hemisphere. Table 1 presents the data classification of the selected days.

\section{Results and discussion}

The upper panel of Fig. 1 shows the resulting mean RTI map for the group of days selected in the summer solstice (see Table 1$)$ under quiet magnetic activity $\left(K_{p} \leq 3^{+}\right)$. The bottom panel of Fig. 1 shows the $\Delta \mathrm{H}$ variation (indicating the EEJ variation), as obtained from the magnetometers in São Luís and Eusébio (as explained above), averaged for the same period of radar observation. The errors bars represent the standard deviation, which is an indication of the day-today variability of the EEJ strength. The vertical dashed lines show, respectively, the sunset time and end of the twilight at the $E$-region altitudes. Thus, Fig. 1 provides a comprehensive diagnostic of the $E$-region dynamics around the $100 \mathrm{~km}$ height and the associated $\Delta \mathrm{H}$ variations due to the EEJ. Figure 2 is similar to Fig. 1, but represents disturbed magnetic condition (that is $K_{p}>3^{+}$) during summer solstice.

An examination of the RTI maps of both figures reveals the regular rise in the EEJ scattering region during the postnoon hours, independent of the geomagnetic condition. Such behavior was first reported for São Luís by Abdu et al. (2002) based on the RESCO data, and more recently, based on the $30-\mathrm{MHz}$ backscatter radar data by de Paula and Hysell (2004). An explanation for this rise has been discussed by Denardini et al. (2005) in terms of the solar zenith angle dependent variation of the peak-production height of an $\alpha$ Chapman layer. This will not be discussed further in this paper.

Another interesting aspect observed in the RTI maps, the focus of the present paper, is the reappearance of a scattering region between about 18:00 LT and 19:30 LT. The time of occurrence of this scatter region matches exactly the time period between sunset and the end of the twilight at about the 108-km height. This region is clearly observed during the magnetically quiet period (Fig. 1), but we note its total absence during the disturbed period (Fig. 2). It is the first time we have observed such scatter regions after sunset in the $E$-region heights, using 50-MHz coherent backscatter radars.

In order to provide information on the type of echoes that dominated the process we have plotted in Fig. 3 a typical RTI map for the quiet period of observation within some corresponding spectrograms covering the height range around the peak power of the RTI. The RTI map from 29 January 2002 is shown in the upper panel with its corresponding spectrograms for the center heights 96.0, 98.6, 101.2, 103.8, 106.4 and $109.0 \mathrm{~km}$. The RTI map covers the range height from 78 to $117 \mathrm{~km}$, while each spectrogram refers to the central height indicated on top of it and corresponds to a height range 


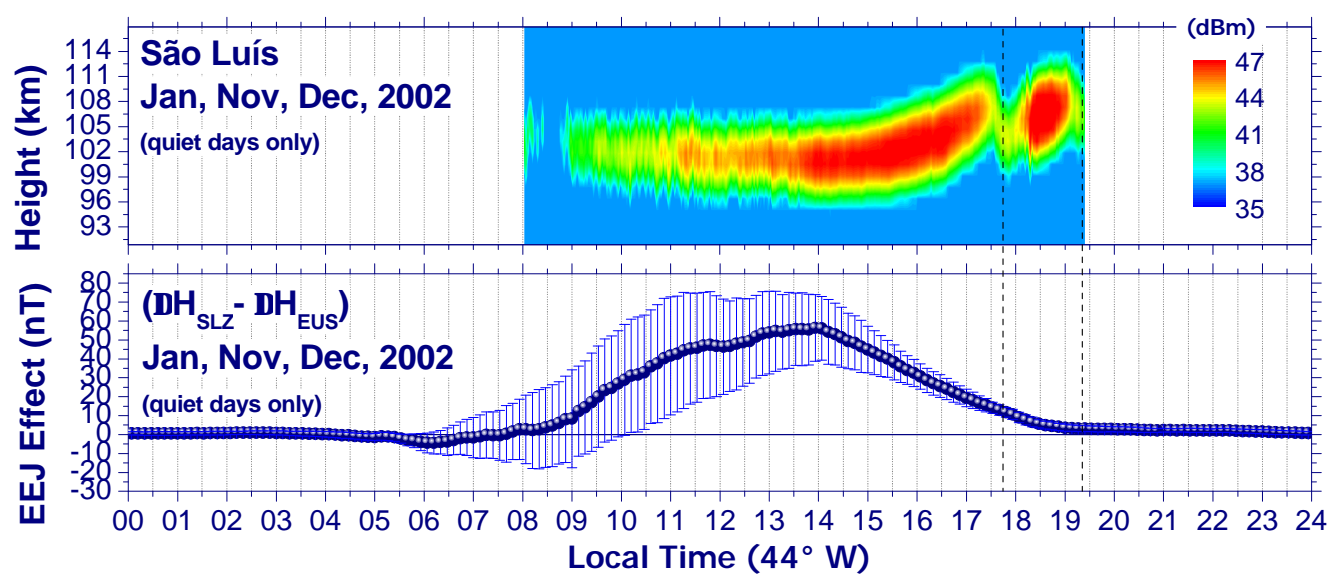

Fig. 1. Upper panel: mean RTI map obtained for the quiet period $\left(K_{p} \leq 3+\right)$ using the RESCO radar during the Southern Hemisphere summer solstice. The colour scale gives the signal power. Bottom panel: Mean diurnal variation of the $\Delta \mathrm{H}=\Delta \mathrm{H}_{S L Z}-\Delta \mathrm{H}_{E U S}$ for the same period of upper mean RTI map, representing the EEJ ground effect (strength), deduced from variations of the H component of the Earth's magnetic field measured by magnetometers in São Luís and Eusébio, respectively.

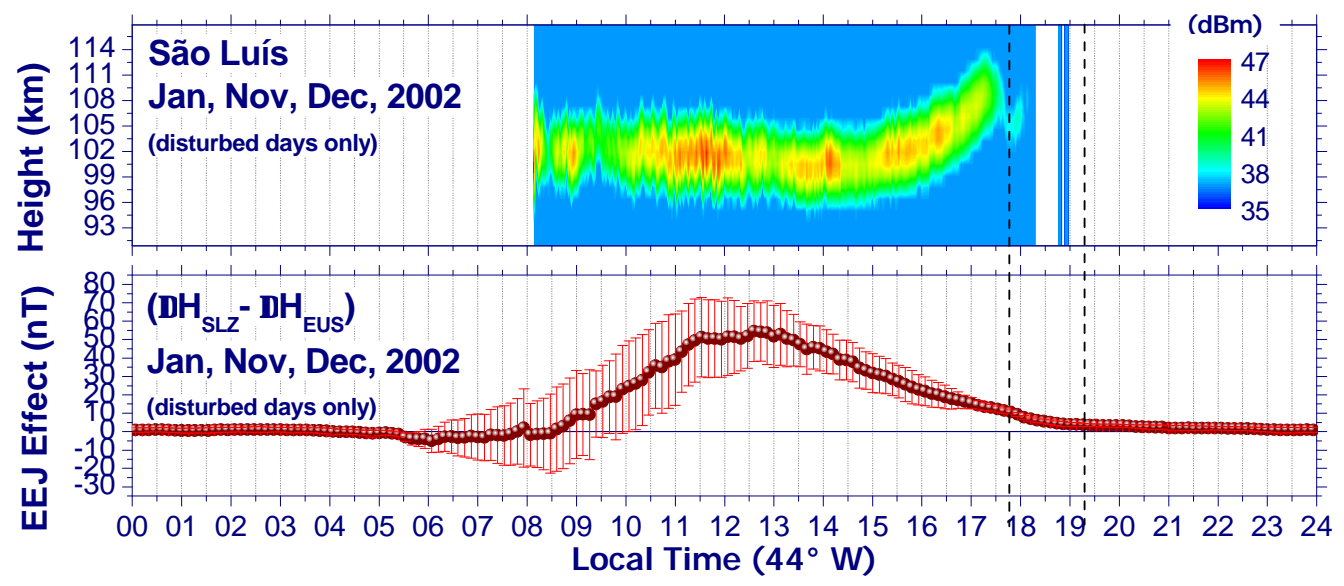

Fig. 2. Same as figure 1 but for the disturbed period $\left(K_{p}>3^{+}\right)$.

of about $2.6 \mathrm{~km}$, as mentioned before. The Doppler velocity on the ordinate of each spectrogram is the radial Doppler velocity of the 3-m irregularities observed by the RESCO.

The spectrograms show the presence of Type I echo and a westward drift velocity (at $\sim 360 \mathrm{~m} / \mathrm{s}$ ), close to local midday, mostly observed above $\sim 101.2 \mathrm{~km}$. They also show Type II echos with westward drift velocity $(<360 \mathrm{~m} / \mathrm{s})$ during almost the whole day at all heights. After about 18:00 LT, the Type II waves seem to dominate the spectra. The Type II echoes are attributed to the plasma irregularities generated through the gradient-drift instability mechanism. They can be excited in the non-homogeneous $E$-region plasma, if an ambient electric field has a large enough component parallel to the background density gradient. In this ambient, electric field, density enhancement regions, as well as the density rarefaction regions are associated with electric field pertur- bations $\delta E$, oppositely directed in the density enhancement and rarefaction regions. By the action $\delta E \times B$, (where $B$ is the Earth's magnetic field horizontal component) the density enhancements are carried in the direction of decreasing background density, while density rarefaction is carried to regions of higher electron density, leading to instability growth if the process occurs faster than plasma diffusion (see Fig. 3.6 on page 31 in Kudeki, 1983).

Figure 4 shows an ionogram from 29 January 2002 obtained at 18:00 LT (21:00 UT) at the radar location. The electron density profile obtained by editing the ionogram, using the SAO-Explorer software of the digisonde (Reinisch et al., 2004 and references therein), is also shown in the figure (blue line). A transparent sporadic $E$-layer trace can be seen in the height region just above $100 \mathrm{~km}$, which is supposed to be the source region for the Type II echoes. An examination 

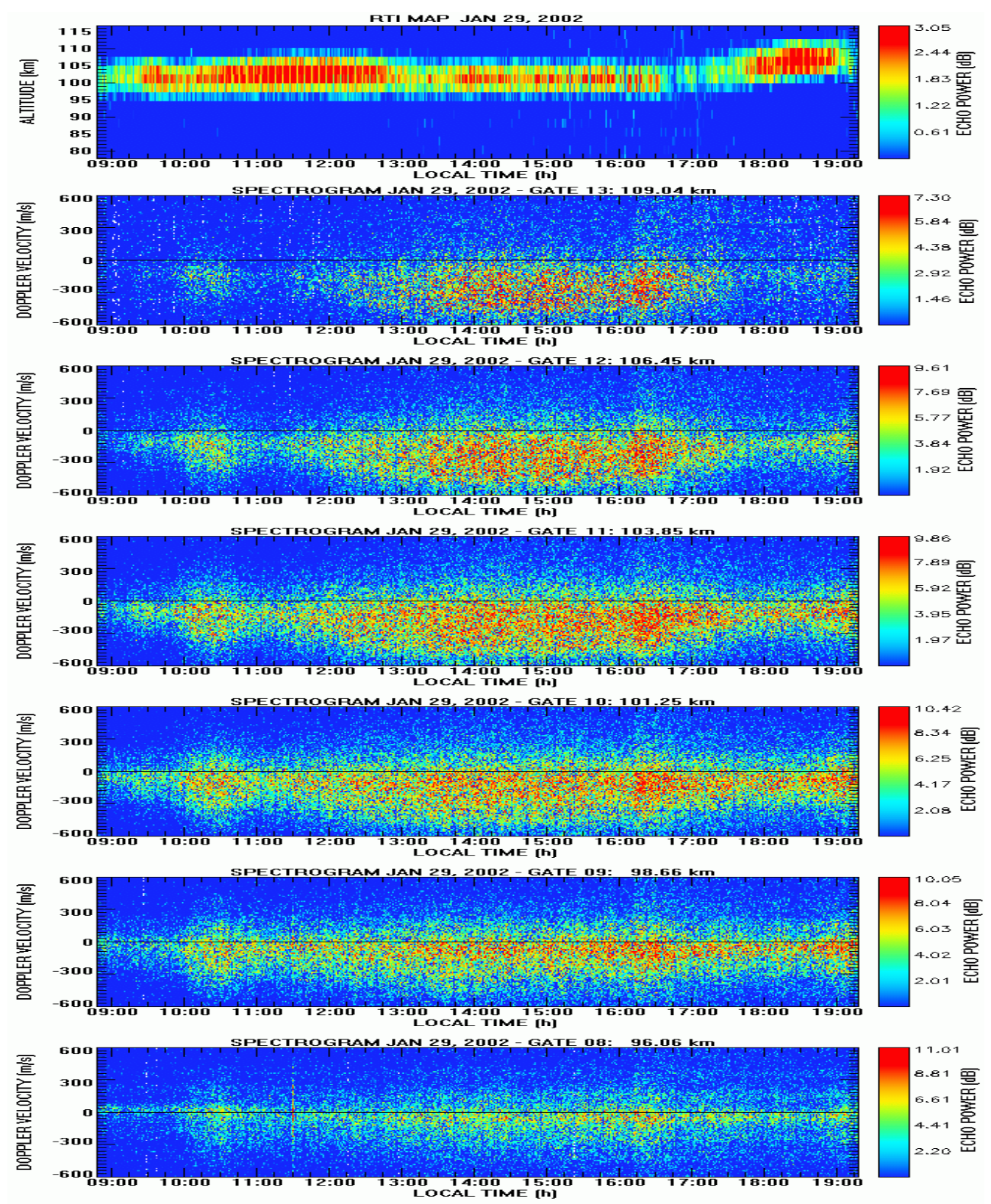

Fig. 3. Upper panel: RTI map from 29 January 2002 with its corresponding spectrograms (from bottom to top) for the center heights 96.0 , $98.6,101.2,103.8,106.4$ and $109.0 \mathrm{~km}$. The color scale beside each map gives the corresponding signal power in dB.

of the electron density profiles vis-à-vis the irregularity trace leads us to infer that the Type II irregularities observed by RESCO must indeed have been generated at the positive (upward) density gradient region just below the $E$-layer electron density peak. The subsequent ionograms (not shown here) indicate an ascent of the $F$-layer trace until close to 19:00 LT, when spread-F started to be observed and impairs the ionogram reading.

Based on the drift velocity direction in the spectrogram and on the consideration that the electron density profile of
Fig. 4 is a true representation of the $E$-region after about 18:00 LT we may conclude that these irregularities are generated through the gradient-drift mechanism, which requires the electric density gradient to be parallel to the electric field (both being upward in this case). The generation of the post 18:00 LT, scattering region (for the Type II irregularities) requires an intensification of the $E$-region vertical (upward) electric field $E_{L}$ that should originate from a correspondingly enhanced eastward electric field $E_{\varphi}$. 


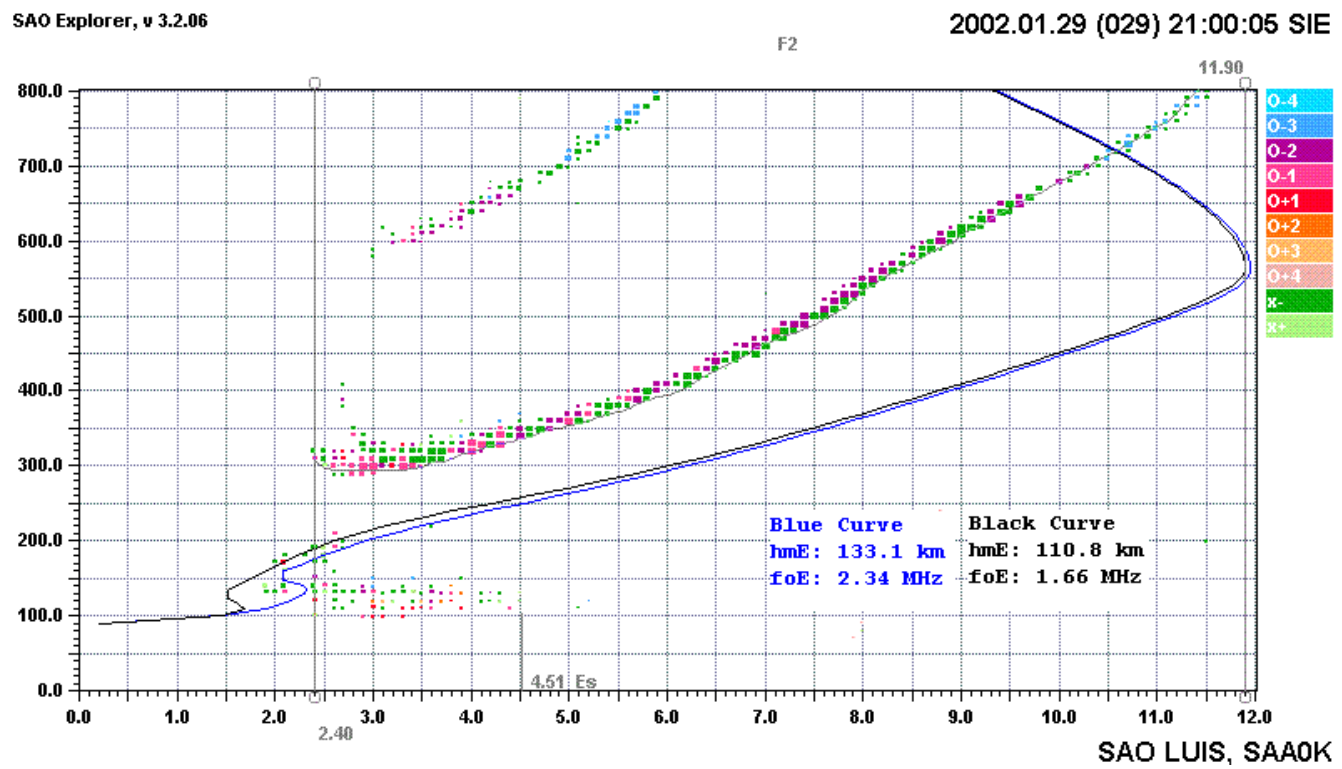

Fig. 4. Ionogram from 29 January 2002 obtained at 18:00 LT (21:00 UT) at São Luís, Brazil, superimposed by its corresponding electron density profile. The black curve was obtained by the SAO-Explorer Automatic Ionogram Scaling Program while the blue curve was obtained after reprocessing the ionogram.

Haerendel and Eccles (1992) investigated the role of EEJ current divergence at sunset in producing the post-sunset enhancement in the $E$-region eastward electric field, as well as its impact on the PRE of the $F$-region. They examined the evening EEJ current system using a flux tube integrated model described by Haerendel et al. (1992), who pointed out that the $F$-region dynamo drives a net vertical current, which has to be supplied from below by a divergence of the horizontal current $J_{\varphi}$ in the equatorial $E$-region. This is achieved by appropriate vertical polarization fields which acts as enhancers to compensate for the decrease in the neutral winds dynamo below the $F_{2}$ region.

Equations (1) give the integrated (a) vertical current $J_{L}$ and (b) horizontal current $J_{\varphi}$ at $F$ region heights (Haerendel et al., 1992), where $U_{\varphi}^{P, H}$ is eastward neutral wind $U_{\varphi}$ weighted by the Pedersen and Hall conductivities, $\Sigma_{P, H}$ are the field line integrated Pedersen and Hall conductivities, $B(L)$ is the magnetic field intensity as a function of the geocentric distance measured in Earth radii, $E_{\varphi, L}$ are the eastward and transverse to $B$ electric fields, $e$ is the electron charge, $\Omega$ is the ion gyrofrequency, $N^{F}$ is the electron density, and $g$ is the gravitational acceleration. The tilde over some quantities indicate that they have different weighting functions in their respective integral (Haerendel and Eccles, 1992):

$$
\begin{aligned}
& J_{L}=\Sigma_{P}\left[E_{L}+B(L) U_{\varphi}^{P}\right]-\Sigma_{H} E_{\varphi} \\
& J_{\varphi}=\tilde{\Sigma}_{P} E_{\varphi}+\Sigma_{H}\left[E_{L}+B(L) U_{\varphi}^{H}\right]+\frac{e g(L)}{\Omega(L)} \tilde{N}^{F} .
\end{aligned}
$$

According to model prediction, neutral winds are small at the $E$-region height. Therefore, for the present case we assume that the neutral wind weighted by the Hall conductivities is most likely small in the evening $E$-region. In addition, the gravitational dynamo can be ignored, so that the integrated vertical current $J_{L}$ and horizontal current $J_{\varphi}$ at $E$ region heights become:

$$
\begin{aligned}
& J_{L}=\Sigma_{P} E_{L}-\Sigma_{H} E_{\varphi} \quad \text { and } \\
& J_{\varphi}=\tilde{\Sigma}_{P} E_{\varphi}+\Sigma_{H} E_{L} .
\end{aligned}
$$

Solving Eq. (2a) for $E_{L}$ will result in:

$E_{L}=\frac{\Sigma_{H}}{\Sigma_{P}} E_{\varphi}+\frac{1}{\Sigma_{P}} J_{L}$.

Inserting Eq. (3) into Eq. (2b) will lead to:

$$
J_{\varphi}=\left(\tilde{\Sigma}_{P}+\frac{\Sigma_{H}^{2}}{\Sigma_{P}}\right) E_{\varphi}+\frac{\Sigma_{H}}{\Sigma_{P}} J_{L},
$$

which differs from the classical EEJ current formulated by Baker and Martyn (1953) by considering a non zero vertical current (the second term in the right-hand side of Eq. 4). Using the current continuity equation, assuming the vertical current to be zero below $75 \mathrm{~km}$ and considering the horizontal electric field to be independent of height, Haerendel and Eccles (1992) have observed that the total vertical current into or out of the top of the $E$-region in a given time interval is equal to the difference in value of the total horizontal current for the same interval. They state that the $F$-region dynamo demands an upward current after sunset, which is 
fed from below the nighttime $F$-region. The upward current $J_{L}$ in the valley region between the $F$-region and the EEJ requires a positive (upward close to the dip equator) $E_{L}$ (Eq. 2a). At this time, the conductivity at the $E$-region drops rapidly due to both recombination and vertical plasma motion, causing an enhancement of the horizontal electric field necessary to maintain the EEJ horizontal current. With increasing $E_{\varphi}$ there is a corresponding increase in $E_{L}$ within EEJ altitudes (Eq. 3). It is relevant to point out here that our previous results from the RESCO radar (Abdu et al., 2002) have identified a region of enhanced drift velocity after 18:00 LT in the height region of $108-110 \mathrm{~km}$ that indicated a significant enhancement of the eastward electric field around this local time. In summary, according to Haerendel and Eccles (1992), the $F$-region dynamo drives a net vertical current in the evening hours, and then, according to Eq. (3), there will be an increase in the equatorial $E$-region vertical electric field $E_{L}$, which is parallel to the upward density gradient (see Fig. 4) necessary to develop a gradient-drift type instability.

The RTI map shown in the Fig. 1 presents the appearance of a scatter region of field-aligned 3-m plasma irregularities just after sunset at about $108 \mathrm{~km}$, when the EEJ polarization electric field was believed to have low values. Therefore, the observation of this region would be an indication that the mechanism proposed by Haerendel and Eccles (1992) could be taking place (see Fig. 10 on page 1191 in Haerendel and Eccles, 1992). If so, the development of $E$-region plasma instabilities at this time and height could provide an experimental verification for their theoretical predictions for the evening ionosphere.

The effect of the EEJ strength at ground level $\left(\triangle \mathrm{H}=\Delta \mathrm{H}_{S L Z}-\Delta \mathrm{H}_{E U S}\right)$, shown in the bottom panel of Fig. 1, does not indicate any increase in the EEJ horizontal current, however. This is mainly due to low conductivity, which we note drops rapidly at this time. Despite the very low values, it is still possible to identify that the EEJ ground strength remains positive during the twilight period, indicating normal EEJ conditions. The error bars in these graphs are the standard deviations of EEJ ground effects related to the averaged values and represent the day-to-day variability of the EEJ itself.

During the selected disturbed period $\left(K_{p}>3^{+}\right)$, the EEJ strength shown in the bottom panel of Fig. 2 indicates that the radar is observing diurnal EEJ irregularities as well. There is no negative excursion of the EEJ induced ground strength after around 18:00 LT. This condition remains until about 20:00 LT, several minutes after the termination of the echoes from the EEJ region. The diurnal variations of the EEJ strength for both the disturbed and quiet periods are very similar. In both cases, the EEJ strength increases in the morning to reach maximum values after the local midday, around 13:00 LT during disturbed days and around 14:00 LT during quiet days. The larger amplitudes of the EEJ dayto-day variability are observed to be in the morning hours, as indicated by the higher standard deviations, which appears to be independent of the disturbance condition for the present analysis. The maximum mean values reached in both cases are only $5 \mathrm{nT}$ apart, and error bars are of the order of $\pm 20 \mathrm{nT}$ at these times. During the selected quiet period, the EEJ ground strength reached 60 nT around 14:00 LT, while it reached about 55 nT around 13:00 LT, during magnetically disturbed conditions. Despite these several similarities noted in the EEJ strength, the scattering region that was observed after about 18:00 LT during the quiet period was not observed during the disturbed period, however. This disappearance/inhibition is an indication that the vertical electric field at this time and height did not have a large enough component parallel to the density gradient to trigger the gradientdrift-instability and/or the density gradient itself was not sufficient for the instability growth (Fejer and Kelley, 1980).

During storm time period the magnetospheric energy input into the auroral region causes heating and expansion of the high-latitude ionospheric-thermospheric system. The acceleration of neutrals through drag force from rapid ion convection under strong electric fields is subsequently responsible for setting off disturbance winds as part of global scale disturbances in the thermospheric general circulation, which in turn, leads to the generation of longer lasting electric fields by wind dynamo, known as Disturbance Dynamo (DD) electric fields. The DD electric fields occur over the middle- and low-latitude regions after some time delay with respect to the initial prompt penetration electric fields (Abdu et al., 2006). Fejer et al. (1999) showed that the evening Jicamarca vertical drifts exhibit the largest downward perturbations due to disturbance dynamo electric fields during equinox solar maximum conditions. Such downward perturbations are caused by disturbance westward electric field (see also Richmond et al., 2003; Abdu et al., 2006). The inclusion of a westward electric field in Eq. (3) causes a decrease in the vertical electric field, or an inversion of the electric field to downward, which could lead to a stable $E$-layer bottom-side density gradient and hence in the disappearance of the scattering region.

Further, if the DD electric fields play an important role in the $F$-layer dynamics, as stated by many authors, it is to be expected that the mechanisms proposed by Haerendel and Eccles (1992), based on a upward current $J_{L}$ in the evening ionosphere, could also be affected in such a way as to decrease the contribution from $J_{L}$, thereby contributing additionally to the disappearance of the scattering region under disturbed conditions, as is observed. Thus, the model proposed by Haerendel and Eccles (1992) seems to explain the dynamics of the $E$-region post-sunset scattering region quite reasonably.

\section{Conclusions}

The present study has shown the following results: the observation of a scattering region in the evening $E$-region; a 
good correlation between the time of occurrence of the scattering region and the pre-reversal enhancement; and the dependence of the plasma irregularities' development with the magnetic disturbance condition. The $E$-region scatter event presented in this study is being reported in the literature for the first time, as far as the authors are aware. It is suggested here that such phenomenon may be associated with increased post-sunset vertical electric fields in the equatorial ionosphere and the consequent generation of $E$-region plasma instabilities (Haerendel and Eccles, 1992). Further, we showed experimental evidences of the development plasma irregularities, with the magnetic disturbance condition. The expectations based on the theory of Haerendel and Eccles (1992) seems to explain reasonably well the occurrence of the scattering region during magnetically quiet conditions and its disappearance under disturbed conditions. An extended study is in progress to verify the seasonal occurrence and dependence of 3-meter plasma instabilities after sunset in the Brazilian sector. It is also intended to determine the relative dominance of the Type I and Type II echoes coming from the scattering region by extending the period of analysis.

Acknowledgements. This work was supported by FAPESP (Fundação de Amparo a Pesquisa de Estado de São Paulo) through thematic project grant no 99/00437. Support received through CNPq (Conselho Nacional de Pesquisa e Desenvolvimento) grants no 520185/95-1 and 304494/2003-08 is also acknowledged. M. A. Abdu wishes to acknowledge the support from CNPq through the process no 520185/95-1. E. R. de Paula was partially supported by CNPq under grant no 502223/91-0. C. M. Wrasse was supported by FAPESP under grant no 05/50482-5. The authors are grateful to the Geomagnetism Research Team of DGE/INPE for kindly provide the geomagnetic data.

Topical Editor M. Pinnock thanks two referees for their help in evaluating this paper.

\section{References}

Abdu, M. A.: Outstanding problems in the equatorial ionospherethermosphere system relevant to spread F, J. Atmos. S.-P., 63 (9), 869-884, 2001.

Abdu, M. A.: Coupling and energetics of the equatorial ionospherethermosphere system: advances during the STEP period, J. Atmos. S.-P., 61 (1-2), 153-165, 1999.

Abdu, M. A., Denardini, C. M., Sobral, J. H. A., Batista, I. S., Muralikrishna, P., and de Paula E. R.: Equatorial electrojet irregularities investigations using a $50 \mathrm{MHz}$ backscatter radar and a digisonde at São Luís: some initial results, J. Atmos. S.-P., 64 (12-14), 1425-1434, 2002.
Abdu, M. A., de Souza, J. R., Sobral, J. H. A., and Batista, I. S.: Magnetic storm associated disturbance dynamo effects over low and equatorial latitude ionosphere, AGU Monograph Corotating Solar Wind Streams and Recurrent Geomagnetic Activity, in press, 2006.

Abdu, M. A., MacDougall, J. W., Batista, I. S., Sobral, J. H. A., and Jayachandran, P. T.: Equatorial evening prereversal electric field enhancement and sporadic E layer disruption: A manifestation of E and F region coupling, J. Geophys. Res., 108 (A6), 1-13, 2003.

Baker, W. G. and Martyn, D. F.: Electric Currents in the Ionosphere .1. The Conductivity, Philosophical Transactions of the Royal Society of London Series a-Mathematical and Physical Sciences, 246 (913), 281-294, 1953.

Çakir, S., Haerendel, G., and Eccles, J. V.: Modeling the Ionospheric Response to Artificially Produced Density Enhancements, J. Geophys. Res., 97 (A2), 1193-1207, 1992.

de Paula, E. R. and Hysell, D. L.: The São Luís $30 \mathrm{MHz}$ coherent scatter ionospheric radar: System description and initial results, Radio Science, 39 (1), 1-11, 2004.

Denardini, C. M., Abdu, M. A., and Sobral, J. H. A.: VHF radar studies of the equatorial electrojet 3-m irregularities over São Luís: day-to-day variabilities under auroral activity and quiet conditions, J. Atmos. S.-P., 66 (17), 1603-1613, 2004.

Denardini, C. M., Abdu, M. A., de Paula, E. R., Sobral, J. H. A., and Wrasse, C. M.: Seasonal characterization of the equatorial electrojet height rise over Brazil as observed by the RESCO $50 \mathrm{MHz}$ backscatter radar, J. Atmos. S.-P., 67 (18), 1665-1673, 2005.

Fejer, B. G.: The Equatorial Ionospheric Electric-Fields - a Review, J. Atmos. S.-P., 43 (5-6), 377-386, 1981.

Fejer, B. G., Scherliess, L., and de Paula, E. R.: Effects of the vertical plasma drift velocity on the generation and evolution of equatorial spread F, J. Geophys. Res., 104 (A9), 19 859-19 869, 1999.

Fejer, B. G., and Kelley, M. C.: Ionospheric Irregularities, Reviews of Geophysics, 18 (2), 401-454, 1980.

Haerendel, G., and Eccles, J. V.: The Role of the Equatorial Electrojet in the Evening Ionosphere, J. Geophys. Res.-Space Physics, 97 (A2), 1181-1192, 1992.

Haerendel, G., Eccles, J. V., and Çakir, S.: Theory for Modeling the Equatorial Evening Ionosphere and the Origin of the Shear in the Horizontal Plasma-Flow, J. Geophys. Res., 97 (A2), 1209-1223, 1992.

Kudeki, E.: Plasma Turbulence in the Electrojet, Ph. D. thesis, Cornell University, Ithaca, NY, USA, 1983.

Reinisch, B. W., Abdu, M. A., Batista, I. S., Sales, G. S., Khmyrov, G., Bullett, T. A., Chau, J., and Rios, V.: Multistation digisonde observations of equatorial spread F in South America, Ann. Geophys., 22(9), 3145-3153, 2004.

Richmond, A. D., Peymirat, C., and Roble, R. G.: Long-lasting disturbances in the equatorial ionospheric electric field simulated with a coupled magnetosphere-ionosphere-thermosphere model, J. Geophys. Res., 108 (A3), 1118, doi:10.1029/2002JA009758, 2003. 